\title{
Isolation and staging of horse seminiferous tubules by transillumination
}

\author{
L. Johnson*, A. F. Kattan-Said*, V. B. Hardy* and W. L. Scrutchfield $\dagger$ \\ Departments of ${ }^{*}$ Veterinary Anatomy and $\dagger$ Large Animal Medicine and Surgery, College of \\ Veterinary Medicine, Institute of Equine Science and Technology, Texas Agricultural Experiment \\ Station, Texas A\&M University, College Station, Texas 77843-4458, USA
}

\begin{abstract}
Summary. Stages of the spermatogenic cycle in the horse were determined by transillumination of enzymically isolated, seminiferous tubules and were verified by wholemounted tubules observed by Nomarski optics and by conventional histology. Isolated tubules were obtained from young ( $<2$ years) and adult (4-10 years) horses by enzymic digestion. Dispersed tubules were separated into three different groups based on the presence, size, and intensity of a dark region in the centre of the tubules: (1) palehomogeneously light, (2) spotty-light on the periphery with a wide spotty region in the central two-thirds, or (3) dark - an intensely dark, narrow region through the central one-third. Seminiferous tubules from young stallions separated easily, but were only of the homogeneously light pattern as they lacked mature spermatids. After observation by Nomarski optics and bright-field microscopy, pale tubules under transillumination largely contained Stages I and II, spotty tubules contained Stages V and VI, and dark tubules contained Stages VII and VIII of the spermatogenic cycle. Invitro incorporation of $\left[{ }^{3} \mathrm{H}\right]$ thymidine in spermatogonia and preleptotene/leptotene primary spermatocytes of these tubules confirmed the viability of germ cells in isolated tubules, and ultrastructural analysis confirmed excellent preservation of normal structure of seminiferous epithelium in isolated tubules. Hence, segments of seminiferous tubules in specific stages of the spermatogenic cycle can be obtained from enzymically digested horse testes when viewed by transillumination.
\end{abstract}

Keywords: seminiferous tubules; spermatogenesis; autoradiography; ultrastructure; transillumination; horse

\section{Introduction}

Staging of isolated rat seminiferous tubules by transillumination, verified by phase-contrast or conventional histology, has allowed biochemical studies on tubular fragments containing specific spermatogenic stages (Parvinen \& Vanha-Perttula, 1972; Parvinen \& Ruokonen, 1982; Morales et al., 1987). These studies have revealed that various biochemical, receptor dynamic, and molecular events in spermatogenesis are stage-dependent.

Using enzymic digestion, whole-mounted seminiferous tubules have been obtained from boars and rams to study the population of undifferentiated spermatogonia (Frankenhuis et al., 1982; Lok et al., 1982). In the horse, staging of enzymically-isolated tubules in toto by Nomarski optics has revealed the spermatogenic wave along the length of the tubule (Johnson et al., 1990).

The objective of the present study was to determine whether enzymically-isolated, equine seminiferous tubules could be successfully staged by transillumination to facilitate biochemical studies on living, staged, tubular fragments. 


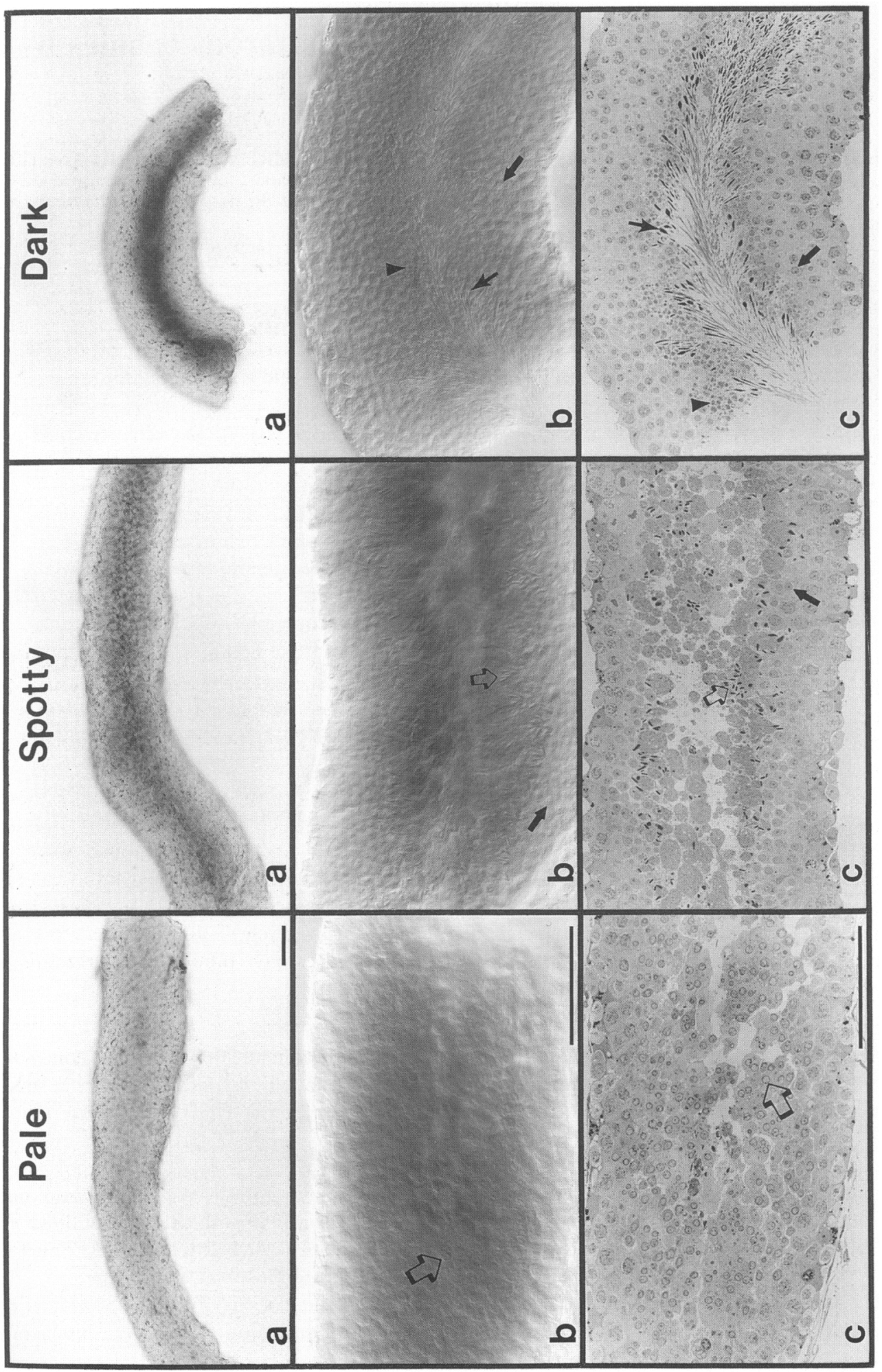

Downloaded from Bioscientifica.com at $04 / 26 / 2023$ 12:55:51PM 


\section{Materials and Methods}

Thin slices $(5-15 \mathrm{~mm})$ of fresh testicular parenchyma from young ( $<2$ years) or aduit (4-10 years) stallions were enzymically digested to isolate seminiferous tubules. Approximately $1 \mathrm{~g}$ tissue was placed in $15 \mathrm{ml}$ of a solution containing phosphate-buffered saline, $0.075 \mathrm{mg}$ hyaluronidase, $5 \mathrm{mg}$ pronase and $0.875 \mathrm{mg}$ collagenase (Johnson et al., 1990). The enzymes were prepared separately on the day of use and mixed just before use. After digestion and agitation at room temperature for $1 \mathrm{~h}$, dispersed tubules were fixed in $2 \%$ glutaraldehyde in $0.1 \mathrm{M}$-cacodylate buffer. While fixation changed the gross appearance from white or brown to more yellow or lighter brown, it did not alter the appearance of tubules when observed by transillumination. Using transillumination, tubules were separated into three groups (pale, spotty and dark) based on the presence, size and intensity of the dark region in the centre of the tubules.

Each group of isolated tubules was studied by Nomarski optics and/or conventional histology of the same tubules to identify the stages represented. Once observed by transillumination, tubules were further fixed with $\mathrm{OsO}_{4}$, dehydrated in graded levels of alcohol, infiltrated with Epon 812, and mounted in toto on glass slides for observation by Nomarski optics (Johnson et al., 1990). For conventional histology using bright-field microscopy, the same tubules were removed from the slides, embedded in Epon 812, sectioned at $1 \mu \mathrm{m}$ and stained with toluidine blue (Johnson \& Neaves, 1981). Staging of tubules mounted in toto or histological sections was based on the presence of specific germ cell types and spermatid development (Swierstra et al., 1974; Johnson, 1985; Johnson et al., 1990).

To determine whether the seminiferous tubules of horses were viable after enzymic isolation, some isolated tubules were incubated in Medium 199 containing $(0 \cdot 1 \mu \mathrm{Ci} / \mathrm{ml})\left[{ }^{3} \mathrm{H}\right]$ thymidine (sp. act. $6.7 \mathrm{Ci} / \mathrm{mmol}$ ) for $10 \mathrm{~min}$. Tubules were washed, fixed in $2 \%$ glutaraldehyde in cacodylate buffer and processed for histological evaluation as described earlier. Epon sections $(1 \mu \mathrm{m})$ were dipped in Kodak NTB-3 photographic emulsion, exposed in the dark at $5^{\circ} \mathrm{C}$ for $2-3$ months, and developed for evaluation by autoradiography (Johnson et al., 1987). Other isolated tubules were processed as indicated above, but Epon blocks were sectioned and processed for electron microscopy (Johnson \& Neaves, 1981).

\section{Results}

In adult horses, three prominent patterns of tubules could be identified by transillumination (Fig. 1). Pale tubules were homogeneously light without a central dark region. Spotty tubules were light on the periphery with a wide spotty region in the central two-thirds. Dark tubules were light on the periphery, but had intensely dark, narrow regions through the central one-third. Occasionally, pale tubules with weak but distinct spots were seen.

Different tubular patterns corresponded to different stages of the cycle. Pale tubules largely corresponded to Stages I and II of the spermatogenic cycle in which neither elongated spermatids nor residual bodies were found (Fig. 1). In some of the tubules, Stage III was also found. Given that spermatogenesis largely is incomplete in horses $<2$ years old, it follows that their testes have only pale seminiferous tubules. In adult horses, pale tubules were composed of regions mostly in Stage I, some in Stage II, and only a few in Stage III of the spermatogenic cycle (Table 1). The spotty tubule corresponds to Stages V and VI (Fig. 1; Table 1). These stages have bundles of spermatids with

Fig. 1. Equine seminiferous tubules observed in toto by transillumination (a), by Nomarski optics (b), or by conventional histology (c). Based on light absorption differences as seen by transillumination, tubules were separated into the following three groups: homogeneously pale tubules without a spotty or dark central region (Pale); tubules with a wide, spotty region in the central two-thirds (Spotty); and tubules with an intensely dark, narrow region in the central one-third (Dark). Using Nomarski optics or conventional histology of these same tubules, the following characteristics were observed: two generations of spermatocytes and one generation of $\mathrm{Sb}_{1}$ spermatids with spherical nuclei (large, open arrow) which are characteristic of Stage I (Pale, b \& c); one generation of spermatocytes and two generations of spermatids [Sa spermatids (thick, closed arrow) and $\mathrm{Sd}_{1}$ spermatids (small, open arrow)] which are characteristic of Stages V and VI (Spotty, b \& c); and two generations of spermatocytes, two generations of spermatids [Sa spermatids (thick, closed arrow) and $\mathrm{Sd}_{2}$ spermatids (thin, closed arrow)] and residual bodies (triangle) which are characteristic of Stage VIII (Dark, b \& c). Bar lengths equal $100 \mu \mathrm{m}$. 
Table 1. Percentages of horse seminiferous tubules containing specific stages

\begin{tabular}{|c|c|c|c|c|c|c|c|c|c|c|}
\hline \multirow{3}{*}{$\begin{array}{l}\text { Transillumination } \\
\text { pattern }\end{array}$} & \multicolumn{2}{|c|}{$\begin{array}{l}\text { Tubular } \\
\text { fragments }\end{array}$} & \multirow{2}{*}{\multicolumn{8}{|c|}{ Spermatogenic stages }} \\
\hline & \multirow[b]{2}{*}{ No. } & \multirow{2}{*}{$\begin{array}{l}\text { Total } \\
\text { length } \\
(\mathrm{mm})\end{array}$} & & & & & & & & \\
\hline & & & I & II & III & IV & $\mathrm{V}$ & VI & VII & VIII \\
\hline Pale & 12 & 12.9 & 100 & 50 & 8 & 0 & 0 & 0 & 0 & 0 \\
\hline Spotty & 9 & $12 \cdot 4$ & 0 & 0 & 0 & 44 & 78 & 78 & 0 & 0 \\
\hline Dark & 13 & $14 \cdot 2$ & 0 & 0 & 0 & 0 & 0 & 8 & 78 & 85 \\
\hline
\end{tabular}

elongated nuclei in the central two-thirds. Dark tubules largely were composed of regions in Stages VII and VIII with the most advanced maturation-phase spermatids and residual bodies. Some pale tubules with distinct small spots corresponded to Stages III and IV, but they were found so rarely that they were not designated as a distinct pattern that could be isolated in sufficient quantity for biochemical studies.

Based on the agreement between patterns observed by transillumination and Nomarski optics or conventional histological bright-field microscopy, fragments of seminiferous tubules representing specific groups of stages were isolated from enzymically digested horse testes and staged by transillumination. Preservation of seminiferous epithelium ultrastructure was normal after enzymic digestion (Fig. 2). Depending on the completeness of digestion, myoid cells sometimes still adhered to the connective tissue components around the seminiferous epithelium. Spermatogonia, located outside the blood-testis barrier, were pulled away from the overlying Sertoli cells and revealed the space of the basal compartment of the seminiferous epithelium. Ultrastructure of Sertoli cells and germ cells was well preserved. Numerous microtubules were observed in the Sertoli cell cytoplasm. Treatment did cause the fusion of profiles of endoplasmic reticulum into continuous intracellular membranes at the base of some of the Sertoli cells. Also, primary spermatocytes had some internal membrane modifications as noted by the fusion of two profiles of endoplasmic reticulum and the deposition of dense substance between the fused profiles. The viability of germ cells after enzymic digestion was indicated by $\left[{ }^{3} \mathrm{H}\right]$ thymidine incorporation into spermatogonia and preleptotene or leptotene primary spermatocytes in isolated tubules (Fig. 3).

\section{Discussion}

Stages of the spermatogenic cycle in enzymically isolated tubular segments observed by transillumination were verified using Nomarski optics of the same tubules mounted in toto and/or bright-field optics of histological sections (Fig. 1). Tubular fragments were isolated from testes by enzymic digestion and teasing of tubules (Johnson et al., 1990). Three major categories of tubules were identified by transillumination. However, some tubular segments were intermediate to the three major categories. In the rat, four categories [(1) pale, (2) weak spots, (3) strong spots, and (4) dark, strong homogeneous dark centre] were originally described (Parvinen \& Vanha-Perttula, 1972). Three of those described for the rat were the same as those described for the horse. Pale tubules with distinct weak spots were seen, but were considered insufficient in number to warrant a separate category.

Only pale tubules were found in seminiferous tubules isolated from horses $<2$ years of age. This can be explained by the fact that spermatogenesis largely is incomplete in horses $<2$ years old (Johnson \& Thompson, 1983). Digestion of testis parenchyma was easier and cleaner tubular preparations were obtained with these younger horses. Ease of tubular isolation probably correlates with the age-related difference in composition of the horse testis interstitium (Johnson \& Neaves, 


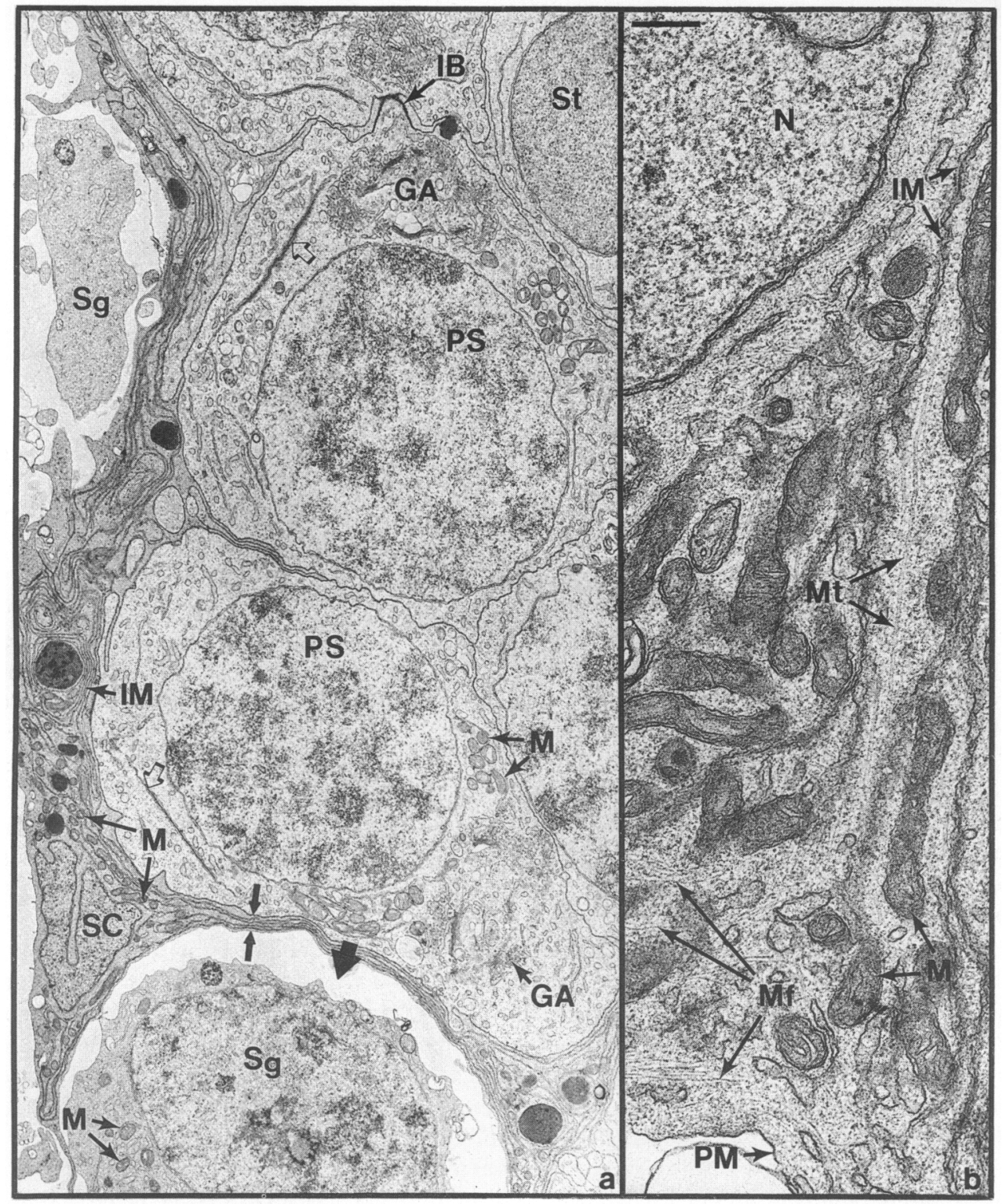

Fig. 2. Transmission electron micrograph of a horse seminiferous tubule isolated by enzymic digestion of the testis. (a) Ultrastructural features of Sertoli cells (SC), spermatogonia ( $\mathrm{Sg}$ ), primary spermatocytes (PS) and spermatids (St) were well preserved after treatment. Mitochondria (M) of Sertoli cells, spermatogonia, primary spermatocytes and Golgi apparatus (GA) of spermatocytes are intact. Space (thick arrow) between spermatogonia and the overlying Sertoli cells (SC) revealed the basal compartment of the seminiferous epithelium. It also revealed the closeness of pachytene primary spermatocytes to the basal compartment, separated by only a thin rim of Sertoli cell cytoplasm (opposing arrows). Space of the basal compartment projected into the Sertoli cell (not shown). In pachytene primary spermatocytes, paired profiles of endoplasmic reticulum (open arrow) were joined with an electron-dense material. This structure is similar in appearance to intercellular bridges (IB) between primary spermatocytes (a \& b). Profiles of Sertoli cell endoplasmic reticulum were fused into continued intracellular membranes (IM). (b) The basal cytoplasm of a Sertoli cell is illustrated, revealing the part of the nucleus (N) and plasma membrane (PM) adjacent to the basal compartment of the seminiferous epithelium. Preservation of microfilaments (Mf), microtubules (Mt) and mitochondria (M) of Sertoli cells was good. Hence, digestion treatment had an effect on intracellular mem-

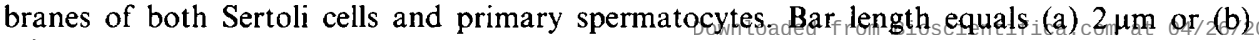
$0 \cdot 3 \mu \mathrm{m}$. 


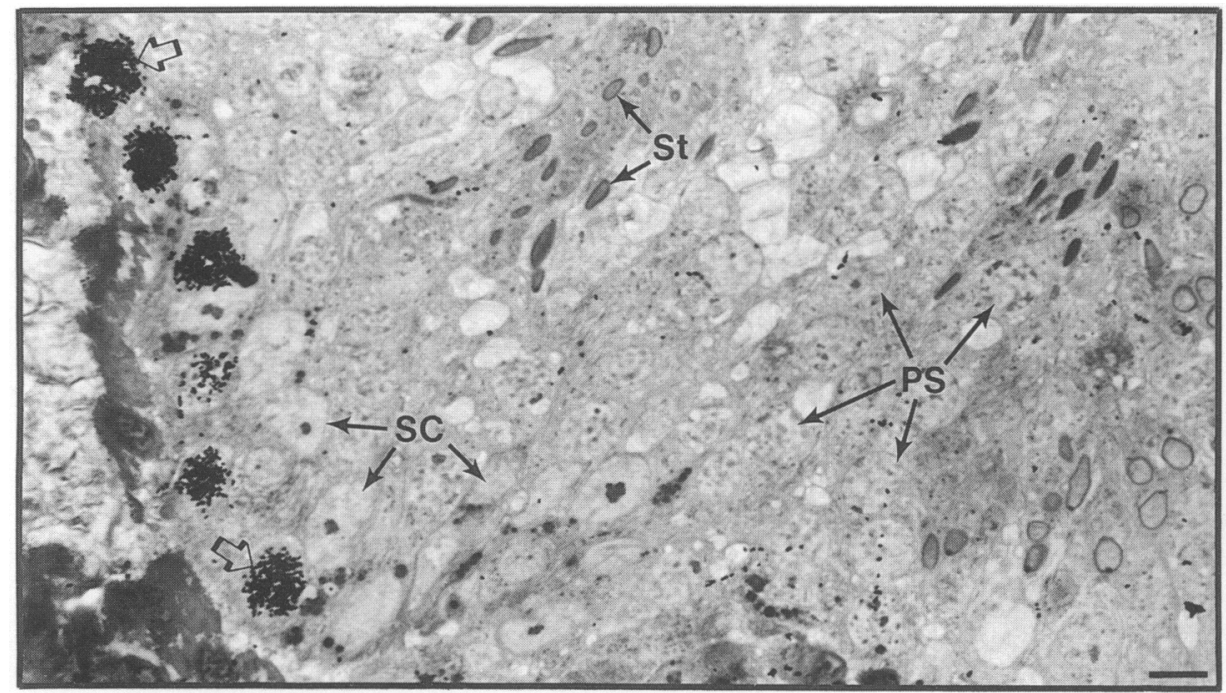

Fig. 3. Photomicrograph of a horse seminiferous tubule isolated and incubated with $\left[{ }^{3} \mathrm{H}\right]$ thymidine. Leptotene primary spermatocytes incorporated $\left[{ }^{3} \mathrm{H}\right]$ thymidine as noted by the intensity of silver grains (arrows) over these nuclei in autoradiographs. Nuclei of Sertoli cells (SC), pachytene primary spermatocytes (PS) and spermatids (St) were not labelled. Bar length equals $10 \mu \mathrm{m}$.

1981). The non-cellular components of the interstitium comprised $16+1 \%$ of the testis parenchyma at age $2-3$ years, $10+1 \%$ at $4-5$ years and $5+1 \%$ for horses $13-20$ years old. Over the same ages that large changes were seen in the interstitium, seminiferous tubules occupied the same proportion of the parenchyma (from $71 \cdot 7+1 \cdot 2$ to $72 \cdot 4+0.6 \%$ ).

As in the rat, the most striking stage difference in the transillumination pattern was observed between tubular segments in the stage in which spermiation occurs (Stage VIII in the horse) and the stage after spermiation (Stage I in the horse), when tubules with the strong dark centre gave way to 1981). The non-cellular components of the interstitium comprised $16+1 \%$ of the testis parenchyma at age $2-3$ years, $10+1 \%$ at $4-5$ years and $5+1 \%$ for horses $13-20$ years old. Over the same ages that large changes were seen in the interstitium, seminiferous tubules occupied the same proportion of the parenchyma (from $71 \cdot 7+1 \cdot 2$ to $72 \cdot 4+0 \cdot 6 \%$ ).

As in the rat, the most striking stage difference in the transillumination pattern was observed between tubular segments in the stage in which spermiation occurs (Stage VIII in the horse) and the stage after spermiation (Stage I in the horse), when tubules with the strong dark centre gave way to homogeneously pale tubules. The acrosome on the horse spermatozoon is small (Johnson, 1990), and so the acrosomal material may not be as important in absorbing light in isolated tubules as that described for the rat (Parvinen \& Vanha-Perttula, 1972). It is more likely that the density of maturation-phase spermatids found near spermiation is more important to light absorption in the horse (Fig. 1).

Ultrastructure of the seminiferous epithelium in isolated tubules was well preserved (Fig. 2). The space of the basal compartment outside the blood-testis barrier was revealed as spermatogonia were pulled apart from the base of Sertoli cells (Fig. 2). These spaces may have been produced by enzymic digestion of bonds between Sertoli cells and spermatogonia. However, these spaces may have resulted from the removal of the underlying myoid cells that are attached to the connective tissue composing the boundary tissue of the seminiferous tubule. Plainly, the myoid cell layer constitutes part of the wall of the basal compartment in which spermatogonia are contained. 
Germ cells of isolated tubules were found to be viable by incorporation of $\left[{ }^{3} \mathrm{H}\right]$ thymidine revealed by autoradiography. Spermatogonia and preleptotene or leptotene primary spermatocytes incorporated a large amount of $\left[{ }^{3} \mathrm{H}\right]$ thymidine during a 10 -min pulse as evident by the large number of silver grains over their nuclei (Fig. 3). These are the same types of germ cells that incorporate $\left[{ }^{3} \mathrm{H}\right]$ thymidine after in-vivo injection into the testicular artery (Swierstra et al., 1974). Parvinen \& Vanha-Perttula (1972) were the first to study stage differences in the position of acrosome and maturation-phase spermatids in the seminiferous epithelium and their effects on light absorbance of unstained tubules. They quantified enzymes in specific stages of the spermatogenic cycle (wave). Further studies have led to the identification of stage-specific differences in RNA synthesis (Soderstrom \& Parvinen, 1976), the production of the living cell method for testing early effects of antispermatogenic compounds (Parvinen \& Parvinen, 1978), the identification of stagespecific differences in androgen binding protein concentration (Ritzen et al., 1981) and in endogenous steroids (Parvinen \& Ruokonen, 1982), and the identification of stage-specific differences in Sertoli cell gene expression (Morales et al., 1987). Likewise, the response of Sertoli cells to FSH is stage dependent (Parvinen, 1982).

The advantage of an isolation technique that allows staging of tubules by transillumination is that germ cells in specific stages are kept in contact with Sertoli cells. This contact is important as Sertoli cells play an essential role in germ cell metabolism (Soderstrom \& Parvinen, 1976). The close association of germ cells with Sertoli cells, readily seen in the horse by transmission electron microscopy (Fig. 2) and by high-voltage electron microscopy of thick Epon sections (Johnson, 1986), illustrates the importance of structural contact of these cells. Recent studies, using tubular fragments from the hamster testis, have illustrated the importance of Sertoli cell-germ cell interaction in the role of glutathione synthesis by germ cells (Den Boer et al., 1989).

The present study provides a method to isolate and determine the stage of the spermatogenic cycle of equine seminiferous tubules when viewed by transillumination (Fig. 1). It also provided evidence that most ultrastructural features of the tubule are normal and that isolated tubules are alive as indicated by their incorporation of $\left[{ }^{3} \mathrm{H}\right]$ thymidine (Fig. 3). However, this study does not provide direct evidence of the usefulness of this approach toward biochemical analysis. Enzymic treatment did cause some modification of the internal membranes of Sertoli and germ cells. Also, depending on the degree of digestion (which can be monitored by microscopic observation of a sample of tubules during the digestion process), myoid cells may be present or absent from the tubules. Myoid cells are known to influence Sertoli functions in vitro (Ailenberg \& Fritz, 1988), and their presence should be considered in biochemical studies. However, relative comparisons of tubules in different stages obtained from the same digestion would be appropriate.

Isolation and staging of seminiferous tubular fragments by transillumination have been successful for rodent species (rat: Parvinen \& Vanha-Perttula, 1972; Parvinen, 1982: Parvinen \& Ruokonen, 1982; mouse: Parvinen \& Hecht, 1981). Isolation of seminiferous tubular fragments by enzymic digestion has revealed the spermatogenic wave in the horse testis (Johnson et al., 1990). The current study extends the usefulness of the technique of isolating tubular fragments by the finding that live tubular fragments obtained by enzymic digestion can be staged by transillumination and used for future studies on changes associated with the stages of the spermatogenic cycle in the horse.

Supported in part by NIH Grant HD16773 and College of Veterinary Medicine Research Enhancement Grant.

\section{References}

Ailenberg, M. \& Fritz, I.B. (1988) Control of levels of plasminogen activator activity secreted by Sertoli cells maintained in a two-chamber assembly. Endocrinology 122, 2613-2618.
Den Boer, P.J., Mackenbach, P. \& Grootegoed, J.A. (1989) Glutathione metabolism in cultured Sertoli cells and spermatogenic cells from hamsters. $J$. Reprod. Fert. 87, 391-400.

Downloaded from Bioscientifica.com at 04/26/2023 12:55:51PM via free access 
Frankenhuis, M.T., Kramer, M.F. \& De Rooij, D.G. (1982) Spermatogenesis in the boar. The Veterinary Quarterly 4, 57-61.

Johnson, L. (1985) Increased daily sperm production in the breeding season of stallions is explained by an elevated population of spermatogonia. Biol. Reprod. 32, $1181-1190$.

Johnson, L. (1986) A new approach to quantification of Sertoli cells that avoids problems associated with the irregular surface. Anat. Rec. 214, 231-237.

Johnson, L. (1990) Spermatogenesis. In Reproduction in Domestic Animals, 4 th edn, in press. Eds. H. H. Cole \& P. T. Cupps. Academic Press, New York.

Johnson, L. \& Neaves, W.B. (1981) Age-related changes in the Leydig cell population, seminiferous tubules, and sperm production in stallions. Biol. Reprod. 24, $703-712$.

Johnson, L. \& Thompson, D.T., Jr (1983) Age-related variation in the Sertolicell population, daily sperm production and serum concentrations of follicle-stimulating hormone, luteinizing hormone and testosterone in stallions. Biol. Reprod. 29, 777-789.

Johnson, L., Matt, K.S., Bartke, A., Nguyen, H.B. \& Lee, H.T. (1987) Effect of photoperiod on the size of the Leydig cell population and the rate of recruitment of Leydig cells in adult Syrian hamsters. Biol. Reprod. 37, 727-738.

Johnson, L., Hardy, V.B. \& Martin, M.T. (1990) Staging equine seminiferous tubules by Nomarski optics in unstained histologic sections and in tubules mounted in toto to reveal the spermatogenic wave. Anat. Rec. 227, (In press.)

Lok, D., Weenk, D. \& de Rooij, D.G. (1982) Morphology, proliferation, and differentiation of undifferentiated spermatogonia in the Chinese hamster and the ram. Anat. Rec. 203, 83-89.
Morales, C., Hugly, S. \& Griswold, M.D. (1987) Stagedependent levels of specific mRNA transcripts in Sertoli cells. Biol. Reprod. 36, 1035-1046.

Parvinen, L.M. \& Parvinen, M. (1978) A "living cell method" for testing the early effects of antispermatogenic compounds: model experiments with two alkylating agents thiotepa and nitrogen mustard. Int. J. Androl., Suppl. 2, 523-537.

Parvinen, M. (1982) Regulation of the seminiferous epithelium. Endocrin. Rev. 3, 404-417.

Parvinen, M. \& Hecht, N.B. (1981) Identification of living spermatogenic cells of the mouse by transilluminationphase contrast microscopic technique for "in situ" analyses of DNA polymerase activities. Histochemistry 71, 567-579.

Parvinen, M. \& Ruokonen, A. (1982) Endogenous steroids in the rat seminiferous tubules. Comparison of the stages of the epithelial cycle isolated by transillumination-assisted microdissection. J. Androl. $3,211-220$.

Parvinen, M. \& Vanha-Perttula, T. (1972) Identification and enzyme quantification of the stages of the seminiferous epithelial wave in the rat. Anat. Rec. 174, 435-450.

Ritzen, E.M., Boitani, C. \& Parvinen, M. (1981) Cyclic secretion of proteins by the rat seminiferous tubule, depending on the stage of spermatogenesis. Int. J. Androl., Suppl. 3, 57-58.

Soderstrom, K.-O. \& Parvinen, M. (1976) RNA synthesis in different stages of rat seminiferous epithelial cycle. Molec. cell. Endocrinol. 5, 181-199.

Swierstra, E.E., Gebauer, M.R. \& Pickett, B.W. (1974) Reproductive physiology of the stallion. I. Spermatogenesis and testis composition. J. Reprod. Fert. 40, 113-123.

Received 4 December 1989 